Acta Cryst. (1987). B43, 198-202

\title{
Molecular-Packing Analysis of Some Glucofuranoimidazolidine Crystals
}

\author{
By M. D. Estrada, A. Conde and R. Márquez \\ Departamento de Física del Estado Sólido, Facultad de Física, Universidad de Sevilla, Spain
}

(Received 8 January 1986; accepted 10 September 1986)

\begin{abstract}
Lattice-energy minimization for seven glucofuranoimidazolidine crystals was carried out in the atom-atom approach using an (exp-6-1) form for atom-pair interactions. Molecular rotation and translation and also internal rotations were optimized along with cell parameters starting from experimental structures. The fit between optimized and observed structures can be considered satisfactory in spite of the existence of hydrogen-bond interactions in the crystals. The contribution of the Coulombic term to the estimated lattice energy was found to be very important but its effect on structural parameters was small.
\end{abstract}

\section{Introduction}

The interpretation of the crystalline state of the matter in terms of the interatomic or intermolecular forces has always been of interest in crystallography, and for organic molecules the atom-atom nonbonded potential-energy model pioneered by Kitaigorodsky (1973) has proven to be a practical approximation. In this model each atom-pair interaction is written as a sum of three terms: a short-range strong repulsive energy due to overlapping electron clouds of filled shells; a weak longer-range attractive dispersion energy; and a very long-range Coulombic energy which can be either repulsive or attractive - between site electrical charges. For hydrocarbons it is generally assumed that the Coulombic-energy term is negligible, but there are organic molecules for which this energy term can be quite important (Williams \& Cox, 1984). However, the force effect of the electrostatic term should be small relative to the energy effect because its functional form causes the energy to vary less with distance than the other energy terms.

In this paper we report the results of energy minimizations on various glucofuranoimidazolidine crystals (see Fig. 1), starting from experimental structures reported elsewhere (see references in Table 1). Previous molecular-packing analyses of compounds (VI) and (VII) have shown a significant cell expansion in some cases. Here, a new set of potential functions is used and also, the Coulombic term in atom-pair interactions is included; the aim was to study the influence of the choice of nonbonded potential parameters and to test the importance of the Coulombic interaction in these compounds.

\section{Calculations}

Lattice-energy calculations in the atom-atom potential approach were performed using the computer program PCK6 (Williams, 1972). In this program the intermolecular lattice energy of a crystal is approximated by pairwise interactions between nonbonded atoms using a form $\Phi=-A r^{-6}+B \exp (-C r)+$ $K_{e} q q^{\prime} / r$ for the potential function describing the interaction between an atom pair. The theoretical model assumes that the molecules are rigid but internal rotations around bonds (subrotations) can be relaxed. In this case additional intramolecular terms for the subrotation conjugation potentials are taken as $E_{c}=E_{c}^{0} \cos ^{2} \varphi$, where $E_{c}^{0}$ is the (negative) conjugation energy for $\varphi=0$. Truncation errors in the evaluation of the lattice sums are virtually eliminated by use of the Ewald-Bertaut-Williams technique for accelerated convergence (Bertaut, 1952; Williams, 1971 ) and a limit of $6 \AA$ was set to ensure convergence to $0.1 \mathrm{~kJ} \mathrm{~mol}^{-1}$. Some attempts with a larger sphere of interaction $(8 \AA$ ) showed no significant influence on the location of energy minima but, as reported by Williams (1974), the reduction of the summation limit to $6 \AA$ slightly improves the agreement with the experimental crystal structure.

The set of potential parameters representing the interactions between electrically neutral atoms included coefficients fitted by Mirskaya (1976) for the

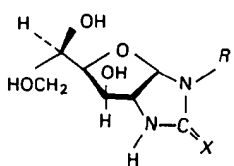

(I) $R=\mathrm{C}_{6} \mathrm{H}_{5}, X=\mathrm{O}$

(ii) $R=\mathrm{C}_{6} \mathrm{H}_{4} \mathrm{Br}, X=\mathrm{S}$

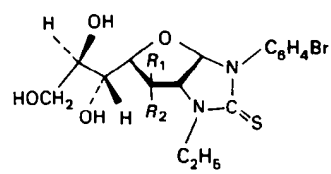

(IV) $R_{1}=\mathrm{H}, R_{2}=\mathrm{OH}$

(VI) $R_{1}=\mathrm{OH}, R_{2}=\mathrm{H}$

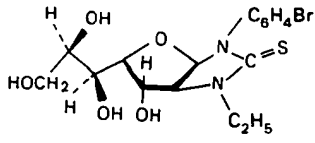

(III)

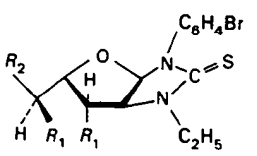

(V) $R_{1}=\mathrm{OH}, R_{2}=\mathrm{HOCH}_{2}$

(VIi) $R_{1}=\mathrm{OAC}, R_{2}=\mathrm{ACOCH}_{2}$
Fig. 1. The glucofuranoimidazolidine crystals studied.

(C) 1987 International Union of Crystallography 


\section{Table 1. Parameter differences from the runs not including a Coulombic contribution}

Shift of centre of mass $\left|\Delta \mathbf{r}_{\mathrm{c}}\right|$ in $\AA$, overall molecular rotation $(\theta)$ and subrotations $\left(\tau_{i}\right)$ in ${ }^{\circ}$ and cell parameters in \%.

\begin{tabular}{|c|c|c|c|c|c|c|c|c|c|c|c|c|c|c|}
\hline \multirow{2}{*}{ Crystal } & & $\left|\Delta \mathbf{r}_{c}\right|$ & $\theta$ & $\Delta a$ & $\Delta b$ & $\Delta c$ & $\Delta \beta$ & $\Delta V$ & $\Delta \tau_{\mathfrak{l}}$ & $\Delta \tau_{2}$ & $\Delta \tau_{3}$ & $\Delta \tau_{4}$ & $\Delta \tau_{5}$ & \multirow{4}{*}{$\begin{array}{c}\text { Ref. } \\
\text { (1) }\end{array}$} \\
\hline & $\begin{array}{l}\text { (a) } \\
\text { (b) }\end{array}$ & $\begin{array}{l}0.37 \\
0.33\end{array}$ & $\begin{array}{l}4 \cdot 1 \\
5 \cdot 2\end{array}$ & & & & & & 1.9 & 4.5 & - & - & - & \\
\hline & (c) & 0.88 & $3 \cdot 2$ & $5 \cdot 1$ & $2 \cdot 6$ & $-1 \cdot 7$ & $-3 \cdot 4$ & 7.6 & & & & & & \\
\hline & (d) & 0.17 & 3.9 & 2.5 & 1.4 & 1.9 & 3.6 & 7.9 & 4.9 & $11 \cdot 0$ & - & - & - & \\
\hline \multirow[t]{4}{*}{ (II) } & (a) & 0.68 & $4 \cdot 0$ & & & & & & & & & & & \multirow[t]{4}{*}{ (2) } \\
\hline & (b) & 0.20 & 7.6 & & & & & & 1.2 & 0.0 & - & - & - & \\
\hline & (c) & 0.49 & $9 \cdot 1$ & 3.6 & 2.8 & $4 \cdot 2$ & - & $11 \cdot 1$ & & & & & & \\
\hline & (d) & 0.30 & 5.7 & 3.6 & 1.6 & 0.5 & - & 6.7 & 9.9 & $1 \cdot 2$ & - & - & - & \\
\hline \multirow[t]{4}{*}{ (III) } & (a) & 0.24 & $7 \cdot 7$ & & & & & & & & & & & \multirow[t]{4}{*}{ (3) } \\
\hline & (b) & 0.03 & 6.6 & & & & & & $3 \cdot 2$ & 0.1 & 0.8 & - & - & \\
\hline & (c) & 0.42 & 6.6 & $18 \cdot 7$ & $-1 \cdot 2$ & -8.9 & & 6.8 & & & & & & \\
\hline & (d) & 0.03 & 6.9 & 0.5 & 0.0 & 0.2 & & 0.8 & 3.5 & 0.1 & 0.8 & - & - & \\
\hline \multirow[t]{4}{*}{ (IV) } & (a) & $0 \cdot 12$ & 3.6 & & & & & & & & & & & \multirow[t]{4}{*}{ (4) } \\
\hline & (b) & $0 \cdot 10$ & 2.6 & & & & & & $2 \cdot 4$ & 2.5 & $1 \cdot 3$ & - & - & \\
\hline & (c) & 0.15 & $4 \cdot 6$ & 1.9 & 2.9 & 1.7 & $-3 \cdot 2$ & 7.8 & & & & & & \\
\hline & (d) & 0.04 & 3.5 & $1 \cdot 1$ & 0.9 & 0.2 & $-2 \cdot 9$ & 3.7 & $1 \cdot 3$ & $3 \cdot 6$ & $1 \cdot 1$ & - & - & \\
\hline \multirow[t]{4}{*}{ (V) } & (a) & $0.28(0.26)$ & $4 \cdot 6(3 \cdot 2)$ & & & & & & & & & & & \multirow[t]{4}{*}{ (5) } \\
\hline & (b) & $0.04(0.03)$ & $4.8(2 \cdot 7)$ & & & & & & $5 \cdot 3$ & 0.5 & 1.4 & - & - & \\
\hline & (c) & $0.03(0.17)$ & $4 \cdot 6(2 \cdot 1)$ & 0.5 & 0.4 & 0.1 & 0.0 & $1 \cdot 1$ & & & & & & \\
\hline & (d) & $0.04(0.03)$ & $5 \cdot 1(2 \cdot 5)$ & 0.7 & 0.6 & 0.1 & 0.0 & $1 \cdot 2$ & $4 \cdot 1$ & 0.7 & $2 \cdot 2$ & - & - & \\
\hline \multirow[t]{4}{*}{ (VI) } & (a) & $0.16(0.10)$ & $9.9(2.9)$ & & & & & & & & & & & \multirow[t]{4}{*}{ (6) } \\
\hline & (b) & $0.10(0.07)$ & $8 \cdot 3(1.4)$ & & & & & & 12.5 & $2 \cdot 2$ & 1.2 & - & - & \\
\hline & (c) & $0.09(0.06)$ & $10.4(2.5)$ & $3 \cdot 1$ & -0.6 & 0.3 & - & $2 \cdot 8$ & & & & & & \\
\hline & (d) & $0.08(0.07)$ & $8.9(2.5)$ & 3.4 & -0.3 & 0.5 & - & 3.6 & 13.0 & $2 \cdot 7$ & $4 \cdot 3$ & - & - & \\
\hline \multirow[t]{4}{*}{ (VII) } & (a) & 0.13 & 2.6 & & & & & & & & & & & \multirow[t]{4}{*}{ (7) } \\
\hline & (b) & 0.04 & $4 \cdot 2$ & & & & & & $5 \cdot 2$ & $4 \cdot 7$ & 4.9 & 11.9 & $4 \cdot 3$ & \\
\hline & (c) & 0.30 & $2 \cdot 2$ & 3.6 & $-2 \cdot 0$ & -0.4 & - & $1 \cdot 1$ & & & & & & \\
\hline & (d) & 0.04 & 4.3 & 0.0 & -0.0 & 0.2 & - & 0.3 & $5 \cdot 1$ & $5 \cdot 4$ & $5 \cdot 2$ & $12 \cdot 4$ & $4 \cdot 3$ & \\
\hline
\end{tabular}

Notes: $(a)$ with cell parameters and torsion fixed at experimental values; $(b)$ with torsion relaxed; $(c)$ with cell parameters relaxed; $(d)$ with torsion and cell parameters relaxed. For crystals (V) and (VI), values in parentheses correspond to the water molecule.

References: (1) Conde, Bernier \& Márquez (1980); (2) Vega, Hernández-Montis \& López-Castro (1976); (3) Estrada, Conde \& Márquez (1983); (4) Estrada, Conde \& Márquez (1984); (5) Conde, Millán, Conde \& Márquez (1985a); (6) Conde, Millán, Conde \& Márquez (1985b); (7) Estrada, Conde \& Márquez (1986).

$\mathrm{C}$ and $\mathrm{H}$ atoms and by Allinger \& Yuh (1980) for the $\mathrm{N}$ atoms. For the $\mathrm{O} \cdots \mathrm{O}$ and $\mathrm{S} \cdots \mathrm{S}$ interactions potential parameters were taken from Mason \& Kreevoy (1955) and Rinaldi \& Pawley (1973) respectively, and for $\mathrm{Br} \cdots \mathrm{Br}$ interactions parameters proposed by Burgos \& Bonadeo (1977) were used. For mixed interactions the arithmetic mean combining rule for the equilibrium interatomic distance, $r_{0}$, and the geometric mean rule for the interaction energy at a distance of $r=r_{0}$ (Mirskaya, 1973) were employed. For the calculations including electrostatic contributions to nonbonded atom interactions the partial

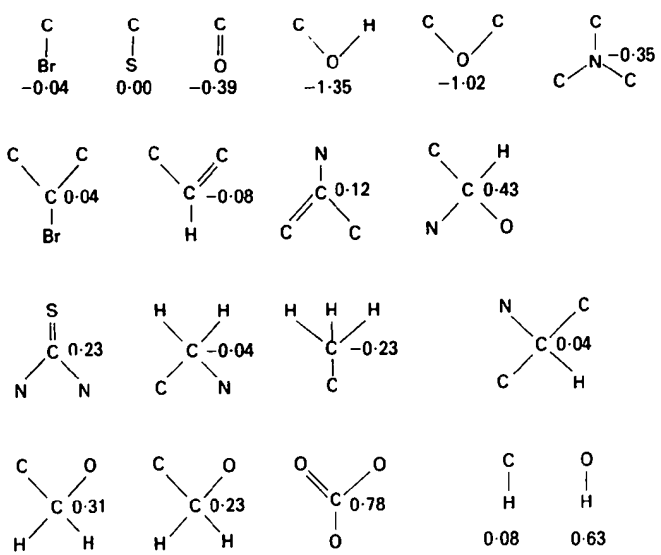

Fig. 2. Illustration of the atomic partial charges (in electronic units) used in the calculations. effective charge at an atom was estimatid from the percentage of covalent character of bonds involving that atom (Skorczyck, 1976). Values of atomic partial charges calculated in this way are illustrated in Fig. 2.

Lattice-energy minimizations were performed with respect to cell constants, molecular translation and rotation, and also subrotation of molecular fragments about selected bonds, starting from the experimental structure. Some previous runs with $\mathrm{H}$-atom positions calculated from the expected geometry showed no significant differences in the optimized atomic parameters and so the published coordinates for $\mathrm{H}$ atoms were used in the reported analyses.

\section{Results}

Representative results of energy minimization runs not including electrostatic contributions are given in Table 1. Four runs were carried out for each compound: in the first, the $\mathrm{X}$-ray molecular structure was retained as a rigid body and the lattice constants were fixed; in the second, subrotations about selected bonds as axes were relaxed; and finally, in the third and fourth runs, cell constants were also included as variable parameters. The molecular subrotations considered are those involving the sugar chain, the phenyl ring, the ethyl group and the acetyl groups (the last two if present). Similar runs including the electrostatic contribution to nonbonded atom interactions 


\section{Table 2. Parameter differences from the runs including a Coulombic contribution}

Shift of centre of mass $\left|\Delta \mathbf{r}_{c}\right|$ in $\AA$, overall molecular rotation $(\theta)$ and subrotations $\left(\tau_{i}\right)$ in ${ }^{\circ}$ and cell parameters in \%. For an explanation of $(a),(b),(c)$, $(d)$ and the use of parentheses see Table 1.

\begin{tabular}{|c|c|c|c|c|c|c|c|c|c|c|c|c|c|}
\hline \multicolumn{2}{|c|}{ Crystal } & $\left|\Delta \mathbf{r}_{c}\right|$ & $\theta$ & $\Delta a$ & $\Delta b$ & $\Delta c$ & $\Delta \beta$ & $\Delta V$ & $\Delta \tau_{1}$ & $\Delta \tau_{2}$ & $\Delta \tau_{3}$ & $\Delta \tau_{4}$ & $\Delta \tau_{5}$ \\
\hline \multirow[t]{4}{*}{ (1) } & (a) & 0.26 & 6.3 & & & & & & & & & & \\
\hline & (b) & 0.20 & 5.9 & & & & & & 0.2 & $4 \cdot 8$ & - & - & - \\
\hline & (c) & 0.13 & $2 \cdot 6$ & 3.7 & $2 \cdot 9$ & -0.7 & $-2 \cdot 2$ & 7.2 & & & & & \\
\hline & (d) & 0.16 & $5 \cdot 4$ & 0.9 & $1 \cdot 4$ & 0.0 & -0.1 & $2 \cdot 4$ & 3.5 & 11.9 & - & - & - \\
\hline \multirow[t]{4}{*}{ (II) } & (a) & 0.27 & 7.8 & & & & & & & & & & \\
\hline & (b) & 0.17 & $7 \cdot 6$ & & & & & & $2 \cdot 3$ & $0 \cdot 1$ & - & - & - \\
\hline & (c) & 0.04 & $8 \cdot 3$ & 0.2 & $1 \cdot 3$ & 3.6 & - & $5 \cdot 1$ & & & & & \\
\hline & (d) & 0.14 & 6.8 & 0.8 & 2.8 & $0 \cdot 1$ & - & 1.2 & $2 \cdot 3$ & $0 \cdot 1$ & - & - & - \\
\hline \multirow[t]{4}{*}{ (III) } & (a) & 0.26 & 6.6 & & & & & & & & & & \\
\hline & (b) & 0.02 & $6 \cdot 3$ & & & & & & 3.5 & $0 \cdot 1$ & 0.3 & - & \\
\hline & (c) & 0.29 & 6.6 & 15.9 & 0.1 & -8.9 & - & 5.8 & & & & & \\
\hline & (d) & 0.03 & 5.8 & 0.3 & 0.0 & 0.2 & - & 0.6 & $2 \cdot 6$ & $0 \cdot 0$ & 0.4 & - & \\
\hline \multirow{4}{*}{ (IV) } & (a) & 0.14 & $2 \cdot 0$ & & & & & & & & & & \\
\hline & (b) & 0.07 & 1.9 & & & & & & 0.8 & 1.7 & 0.8 & - & \\
\hline & (c) & 0.04 & $4 \cdot 2$ & 0.3 & 0.3 & $0 \cdot 1$ & $-2 \cdot 0$ & $1 \cdot 3$ & & & 00 & - & \\
\hline & (d) & 0.05 & 1.7 & 0.6 & 1.0 & $0 \cdot 2$ & $-2 \cdot 2$ & $2 \cdot 2$ & $4 \cdot 7$ & $4 \cdot 2$ & $1 \cdot 2$ & - & - \\
\hline \multirow{4}{*}{ (V) } & (a) & $0.11(0.11)$ & $3 \cdot 1(6 \cdot 2)$ & & & & & & & & & & \\
\hline & (b) & $0.08(0.08)$ & $3 \cdot 3(3 \cdot 5)$ & & & & & & 6.6 & $1 \cdot 3$ & $3 \cdot 4$ & - & - \\
\hline & (c) & $0.05(0.04)$ & $3 \cdot 6(2 \cdot 1)$ & 0.5 & 0.5 & 0.1 & 0.0 & 1.8 & & . & . & 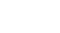 & - \\
\hline & (d) & $0.05(0.04)$ & $3 \cdot 6(2 \cdot 3)$ & 0.7 & 0.6 & 0.0 & 0.5 & $1 \cdot 1$ & $4 \cdot 5$ & 0.9 & 2.8 & - & - \\
\hline \multirow[t]{4}{*}{ (VI) } & (a) & $0.15(0.07)$ & $9 \cdot 0(2 \cdot 7)$ & & & & & & & & & & \\
\hline & (b) & $0.09(0.07)$ & $7 \cdot 2(2 \cdot 3)$ & & & & & & $8 \cdot 3$ & 2.6 & 1.6 & - & - \\
\hline & (c) & $0.09(0.06)$ & $8.8(3.5)$ & $2 \cdot 8$ & -0.6 & 0.4 & - & 2.5 & & & & & \\
\hline & (d) & $0.07(0.07)$ & $6.9(3 \cdot 2)$ & 1.9 & -0.4 & 0.4 & - & 1.9 & 10.8 & $2 \cdot 3$ & 2.5 & - & - \\
\hline \multirow{4}{*}{ (VII) } & (a) & $1 \cdot 10$ & $2 \cdot 6$ & & & & & & & & & & \\
\hline & (b) & 0.08 & $2 \cdot 3$ & & & & & & 3.9 & $3 \cdot 1$ & 5.9 & $15 \cdot 0$ & $13 \cdot 2$ \\
\hline & (c) & 0.27 & $2 \cdot 0$ & $3 \cdot 4$ & $-2 \cdot 0$ & -0.9 & - & 0.5 & & & & & \\
\hline & (d) & 0.04 & $3 \cdot 4$ & 0.0 & 0.0 & 0.1 & - & 0.2 & 3.6 & $4 \cdot 3$ & 4.9 & 12.7 & 5.4 \\
\hline
\end{tabular}

were also carried out and the results are summarized in Table 2.

The theoretical configuration agrees with the experimental structure in all cases, in spite of the existence of intermolecular hydrogen-bond interactions, the presence in two crystals of a hydration water molecule involved in the hydrogen-bond scheme, and the presence in the molecule of $S$ and $\mathrm{Br}$ atoms for which potential functions are not as well established as for $\mathrm{C}$ and $\mathrm{H}$ atoms.

The inclusion of the cell parameters as variables generally leads to an expansion of the cell. This unexpected feature may be attributed to the approach used, in which the hydrogen-bond contacts are represented by van der Waals functions. This results in a higher contribution of the repulsive term, and the contacts are expanded. In fact, cell expansion is found generally for those directions along which hydrogenbond chains occur in the crystal. However, previous calculations for compound (VI) (Conde, Millán, Conde \& Márquez, 1985b) using another set of potential parameters for $\mathrm{C}$ and $\mathrm{H}$ atoms, show analogous qualitative features but the cell expansion was more significant. So, the effect seems to exist, but the choice of nonbonded potential parameters is also important.

As is known, the use of a nonbonded pairwise potential for the atoms involved in a hydrogen bond introduces a large repulsive interaction where a moderately attractive interaction should exist. In order to avoid this unwanted effect calculations have also been carried out by 'turning off' these interactions, i.e. by omitting the $\mathrm{H}$ atoms involved from the calculations. In this way, the spurious repulsive interaction in the

hydrogen bonds is avoided but the contributions of some van der Waals interactions (those involving the omitted $\mathrm{H}$ atoms) are also eliminated. Results of energy minimization runs using this strategy for either (exp-6) and (exp-6-1) potential functions are summarized in Tables 3 and 4, respectively.

As can be seen, the fit between experimental and optimized structures is improved, in general, with respect to the above results (Tables 1 and 2), and the lattice expansion (when present) is appreciably lower. All the optimized structures remain very similar with regard to the molecular parameters and the torsions of the selected subrotations. In general shifts of the positional and orientational molecular parameters are also significantly reduced when the hydrogen-bond interactions are turned off, as can be observed by comparison of the results of Tables 1 and 3 and Tables 2 and 4, respectively. For the last calculations (Tables 3 and 4), molecular translation is lower than $0 \cdot 25 \AA$ in all cases and the overall molecular rotation is lower than $4.5(10.8)^{\circ}$ for runs not including (including) an electrostatic term. For the calculations including hydrogen-bond interactions (Tables 1 and 2), the molecular shifts were $0.3(0.9) \AA$ and $9.0(10.4)^{\circ}$ for runs including (not including) an electrostatic contribution. Torsion angles of selected molecular fragments are reproduced within $6^{\circ}$ except for the sugar chain in compounds (II), (VI) and (VII), and for the acetyl groups in compound (VII). As can be seen, the variation in the torsion angle of phenyl group in compound $(\mathrm{I})\left(<12^{\circ}\right)$ is greatly reduced $\left(\sim 1^{\circ}\right)$ when hydrogen-bond interactions are not included. In this respect it should be noted that only compound (I) 
Table 3. Parameter differences from the runs not including a Coulombic contribution (hydrogen bonds omitted)

Shift of centre of mass $\left|\Delta \mathbf{r}_{c}\right|$ in $\AA$, overall molecular rotation $(\theta)$ and subrotations $\left(\tau_{i}\right)$ in ${ }^{\circ}$ and cell parameters in \%. For an explanation of $(a),(b),(c)$, $(d)$ and the use of parentheses see Table 1 .

\begin{tabular}{|c|c|c|c|c|c|c|c|c|c|c|c|c|c|}
\hline Crystal & & $\left|\Delta \mathbf{r}_{c}\right|$ & $\theta$ & $\Delta a$ & $\Delta b$ & $\Delta c$ & $\Delta \boldsymbol{\beta}$ & $\Delta V$ & $\Delta \tau_{1}$ & $\Delta \tau_{2}$ & $\Delta \tau_{3}$ & $\Delta \tau_{4}$ & $\Delta \tau_{s}$ \\
\hline (I) & $\begin{array}{l}(a) \\
\text { (b) }\end{array}$ & $\begin{array}{l}0.25 \\
0.23\end{array}$ & $\begin{array}{l}1.9 \\
3.7\end{array}$ & & & & & & 0.9 & 2.5 & - & - & - \\
\hline & (c) & 0.09 & 2.5 & 0.8 & 0.2 & 0.7 & $2 \cdot 8$ & $3 \cdot 1$ & & & & & \\
\hline & (d) & 0.07 & $2 \cdot 4$ & $0 \cdot 6$ & 0.1 & 0.4 & $-3 \cdot 3$ & $2 \cdot 6$ & 0.1 & $1 \cdot 2$ & - & - & - \\
\hline (II) & (a) & 0.13 & 0.6 & & & & & & & & & & \\
\hline & (b) & 0.10 & 1.4 & & & & & & 0.3 & $6 \cdot 1$ & - & - & - \\
\hline & (c) & 0.11 & 0.8 & $-0 \cdot 2$ & 0.4 & 0.2 & - & 0.4 & & & & & \\
\hline & (d) & 0.09 & 1.5 & 0.0 & 0.5 & 0.2 & - & 0.7 & $1 \cdot 1$ & $8 \cdot 2$ & - & - & - \\
\hline (III) & (a) & 0.04 & 1.5 & & & & & & & & & & \\
\hline & (b) & 0.01 & $1 \cdot 1$ & & & & & & 3.4 & $1 \cdot 0$ & $1 \cdot 3$ & - & - \\
\hline & (c) & 0.08 & $1 \cdot 6$ & $1 \cdot 1$ & 0.1 & 0.2 & - & 1.5 & & & & & \\
\hline & (d) & 0.00 & $1 \cdot 3$ & $0 \cdot 0$ & 0.0 & 0.1 & - & 0.1 & 1.4 & 0.6 & $0 \cdot 3$ & - & - \\
\hline (IV) & (a) & 0.00 & 0.9 & & & & & & & & & & \\
\hline & (b) & 0.00 & $1 \cdot 0$ & & & & & & 0.8 & 0.2 & 0.5 & - & - \\
\hline & (c) & 0.00 & 0.9 & 0.0 & 0.2 & 0.2 & $0 \cdot 0$ & $0 \cdot 0$ & & & & & \\
\hline & (d) & 0.03 & $1 \cdot 8$ & -0.1 & 0.1 & $0 \cdot 0$ & 0.6 & $-0 \cdot 1$ & $2 \cdot 0$ & 0.6 & $1 \cdot 1$ & - & - \\
\hline (v) & (a) & $0.17(0.08)$ & $2 \cdot 2(1 \cdot 9)$ & & & & & & & & & & \\
\hline & (b) & $0.04(0.04)$ & $2.5(0.4)$ & & & & & & $4 \cdot 2$ & $2 \cdot 3$ & $4 \cdot 7$ & & \\
\hline & (c) & $0.00(0.00)$ & $0.4(0.0)$ & 0.0 & 0.0 & 0.0 & $1 \cdot 4$ & $-0 \cdot 3$ & & & & & \\
\hline & (d) & $0.03(0.02)$ & $2.1(0.5)$ & 0.1 & -0.1 & $-0 \cdot 1$ & $1 \cdot 7$ & -0.5 & $2 \cdot 4$ & 0.5 & $2 \cdot 4$ & - & - \\
\hline (VI) & (a) & $0.10(0.12)$ & $1.0(1.5)$ & & & & & & & & & & \\
\hline & (b) & $0.07(0.09)$ & $2.1(3.5)$ & & & & & & 4.5 & 1.9 & $15 \cdot 8$ & - & - \\
\hline & (c) & $0.08(0 \cdot 10)$ & $4 \cdot 5(3 \cdot 1)$ & 1.4 & 0.0 & 0.2 & - & 1.6 & & & & & \\
\hline & (d) & $0.12(0.14)$ & $2 \cdot 2(3 \cdot 7)$ & $2 \cdot 2$ & -0.5 & 0.3 & - & $2 \cdot 0$ & 8.5 & $13 \cdot 2$ & $12 \cdot 2$ & - & - \\
\hline (VII) & (a) & 0.04 & 0.9 & & & & & & & & & & \\
\hline & (b) & 0.05 & $3 \cdot 4$ & & & & & & $4 \cdot 2$ & 10.4 & 3.6 & $2 \cdot 8$ & 9.5 \\
\hline & (c) & 0.12 & 0.6 & 0.1 & -0.1 & -0.8 & - & $-1 \cdot 7$ & & & & & \\
\hline & (d) & 0.01 & $2 \cdot 2$ & 0.0 & 0.0 & 0.0 & - & $-0 \cdot 2$ & 1.9 & $4 \cdot 3$ & 1.4 & 1.9 & 4.5 \\
\hline
\end{tabular}

Table 4. Parameter differences from the runs including a Coulombic contribution (hydrogen bonds omitted)

Shift of centre of mass $\left|\Delta \mathbf{r}_{c}\right|$ in $\AA$, overall molecular rotation $(\theta)$ and subrotations $\left(\tau_{i}\right)$ in ${ }^{\circ}$ and cell parameters in \%. For an explanation of $(a),(b),(c)$, (d) and the use of parentheses see Table 1 .

\begin{tabular}{|c|c|c|c|c|c|c|c|c|c|c|c|c|c|}
\hline \multicolumn{2}{|l|}{ Crystal } & $\left|\Delta \mathbf{r}_{c}\right|$ & $\theta$ & $\Delta a$ & $\Delta b$ & $\Delta c$ & $\Delta \beta$ & $\Delta V$ & $\Delta \tau_{1}$ & $\Delta \tau_{2}$ & $\Delta \tau_{3}$ & $\Delta \tau_{4}$ & $\Delta \tau_{5}$ \\
\hline \multirow[t]{3}{*}{ (I) } & $\begin{array}{l}(a) \\
\text { (b) }\end{array}$ & $\begin{array}{l}0.25 \\
0.20\end{array}$ & $\begin{array}{l}5.8 \\
6.6\end{array}$ & & & & & & 0.9 & 0.8 & - & - & - \\
\hline & (c) & 0.05 & 5.3 & $4.0^{\circ}$ & -2.0 & $2 \cdot 2$ & 0.7 & 3.8 & & & & & \\
\hline & (d) & 0.08 & 3.9 & 0.8 & 0.0 & 0.2 & -1.8 & $2 \cdot 0$ & 0.9 & $1 \cdot 1$ & - & - & - \\
\hline \multirow[t]{4}{*}{ (II) } & (a) & 0.22 & $6 \cdot 1$ & & & & & & & & & & \\
\hline & (b) & 0.09 & 7.6 & & & & & & $2 \cdot 4$ & 2.9 & - & - & - \\
\hline & (c) & 0.14 & 7.4 & 5.5 & 0.4 & 0.3 & - & 6.2 & & & & & \\
\hline & (d) & 0.13 & $8 \cdot 2$ & $5 \cdot 7$ & 0.5 & 0.3 & - & 6.6 & 5.5 & $11 \cdot 3$ & - & - & - \\
\hline \multirow[t]{4}{*}{ (III) } & (a) & 0.14 & 1.6 & & & & & & & & & & \\
\hline & (b) & 0.06 & $2 \cdot 4$ & & & & & & $3 \cdot 2$ & 8.4 & 2.8 & - & - \\
\hline & (c) & 0.06 & $3 \cdot 3$ & 0.9 & 0.1 & 1.2 & - & $2 \cdot 2$ & & & & & \\
\hline & (d) & 0.05 & 2.7 & $1 \cdot 1$ & 0.0 & 1.9 & - & 3.0 & 4.9 & $7 \cdot 6$ & $4 \cdot 8$ & - & - \\
\hline \multirow[t]{4}{*}{ (IV) } & (a) & 0.05 & $2 \cdot 1$ & & & & & & & & & & \\
\hline & (b) & 0.06 & 0.6 & & & & & & 3.7 & $3 \cdot 2$ & $1 \cdot 1$ & - & - \\
\hline & (c) & 1.43 & $2 \cdot 6$ & -0.1 & 1.5 & $3 \cdot 1$ & -0.9 & $4 \cdot 7$ & & & & & \\
\hline & (d) & 0.02 & $1 \cdot 0$ & 0.0 & 0.3 & 0.1 & $1 \cdot 1$ & 0.7 & $2 \cdot 9$ & $2 \cdot 6$ & 1.5 & - & - \\
\hline \multirow[t]{4}{*}{ (V) } & (a) & $0.05(0.13)$ & $3.9(2 \cdot 1)$ & & & & & & & & & & \\
\hline & (b) & $0.06(0.10)$ & $5.9(1.7)$ & & & & & & 1.8 & 6.6 & 5.0 & - & - \\
\hline & (c) & $0.01(0.04)$ & $6.8(0.5)$ & 0.0 & 0.0 & 0.0 & 9.5 & 1.5 & & & & & \\
\hline & (d) & $0.01(0.01)$ & $6 \cdot 1(0.0)$ & 0.0 & 0.0 & 0.0 & 1.6 & 0.0 & 0.6 & 1.7 & 0.9 & - & - \\
\hline \multirow[t]{4}{*}{ (VI) } & (a) & $0.19(0.13)$ & $10 \cdot 3(6 \cdot 7)$ & & & & & & & & & & \\
\hline & (b) & $0.23(0.19)$ & $9 \cdot 5(9 \cdot 8)$ & & & & & & $2 \cdot 8$ & 17.7 & 15.7 & - & - \\
\hline & (c) & $0.13(0.11)$ & $10 \cdot 8(7 \cdot 8)$ & $4 \cdot 5$ & 0.1 & 0.1 & - & $4 \cdot 7$ & & & & & \\
\hline & (d) & $0.08(0.17)$ & $10 \cdot 1(10 \cdot 1)$ & $4 \cdot 5$ & 0.4 & 0.2 & - & $5 \cdot 1$ & $3 \cdot 1$ & 17.4 & $17 \cdot 3$ & - & - \\
\hline \multirow[t]{4}{*}{ (VII) } & (a) & 0.04 & & & & & & & & & & & \\
\hline & (b) & 0.08 & $2 \cdot 0$ & & & & & & $4 \cdot 3$ & $6 \cdot 3$ & 3.9 & $2 \cdot 6$ & $10 \cdot 1$ \\
\hline & (c) & 0.14 & 0.4 & $1 \cdot 0$ & $-1 \cdot 1$ & $-2 \cdot 2$ & - & $2 \cdot 2$ & & & & & \\
\hline & (d) & 0.05 & $3 \cdot 1$ & 0.1 & -0.1 & -0.7 & - & -0.7 & $4 \cdot 1$ & 6.4 & 4.4 & $2 \cdot 6$ & $9 \cdot 1$ \\
\hline
\end{tabular}

exhibits a hydrogen bond involving atoms of the phenyl ring and this could, perhaps, be the reason for the anomalously low torsion angle of the phenylimidazolidine rings in this compound.

On the other hand, it can be seen that significantly higher shifts occur for overall molecular rotation and torsional angles in compound (VI), especially when the electrostatic term is included. This is the only case where the fit between experimental and optimized structures is better when hydrogen-bond interactions are included (Tables 1 and 2 ) and could be associated with the existence of water molecules in the cell. 
Even though the calculated values for the lattice energy could not be directly compared with the experimental ones because of the limitations of the approach used, it can be illustrative to compare the values obtained in the different runs when the hydrogen bonds are omitted. When the electrostatic term is not included, values of the lattice energy for rigid molecules (no subrotations) are in the range $70-100 \mathrm{~kJ} \mathrm{~mol}^{-1}$, whereas when molecular subrotations are relaxed lattice-energy values are in the range $100-160 \mathrm{~kJ} \mathrm{~mol}^{-1}$. For runs including the electrostatic term, the lattice energy is in the range 100 $170 \mathrm{~kJ} \mathrm{~mol}^{-1}$ when rigid molecules are considered and $130-200 \mathrm{~kJ} \mathrm{~mol}^{-1}$ when molecular subrotations are relaxed. So, an unexpectedly large Coulombic contribution to the lattice energy, ranging from 30 to $60 \%$ of the total estimated lattice energy, is found. In our opinion, this high contribution is a qualitatively significant feature, in spite of the approach and the potential parameters used and the method of estimating effective atomic charges. Generally, it was tacitly assumed that the Coulombic contribution to the lattice energy is negligible but some previous results indicate that this assumption is not valid in all hydrocarbon crystals, reaching a value of $29 \%$ of the total lattice energy of benzene and up to $59 \%$ in other cases (Williams \& Cox, 1984).

If the Coulombic contribution to the lattice energy seems to be significant for these crystals, it is true, however, that the inclusion of the electrostatic term does not significantly affect the values of the optimized structural parameters. The overall fit between the theoretical configuration and experimental structure is, in general, slightly more satisfactory for runs including the electrostatic contribution, but conclusive general results on the effects of its inclusion on molecular rotation and translation would be difficult to establish.
Within the limits of the approach and the potential functions used, we think that the reported results clearly indicate that the electrostatic term makes an important contribution to the lattice energy of these compounds but has little effect on the optimized structural parameters. A major limitation for accuracy in these calculations, in our opinion, is the description of the hydrogen bonds, but further improvements should be possible by defining a realistic potential function for these interactions.

\section{References}

Allinger, N. L. \& YUH, Y. (1980). Quantum Chemistry Program Exchange, 12, 395. Indiana Univ.

Bertaut, F. (1952). J. Phys. 13, 499-505.

Burgos, E. \& Bonadeo, H. (1977). Chem. Phys. Lett. 49, 475-478. Conde, A., Bernier, F. \& Márquez, R. (1980). Acta Cryst. B36, 3048-3052.

Conde, C. F., Millán, M., Conde, A. \& Márquez, R. (1985a). Acta. Cryst. C41, 277-280.

Conde, C. F., Millán, M., Conde, A. \& Márquez, R. (1985b). Acta Cryst. C41, 1658-1662.

Estrada, M. D., Conde, A. \& Márquez, R. (1983). Acta Cryst. C39, 1418-1421.

Estrada, M. D., Conde, A. \& MÁrquez, R. (1984). Acta Cryst. C40, 898-901.

Estrada, M. D., Conde, A. \& Márquez, R. (1986). Acta Cryst. C42, 454-457.

KiTAIGORODSKY, A. I. (1973). Molecular Crystals and Molecules. New York: Academic Press.

Mason, A. \& Kreevoy, M. M. (1955). J. Am. Chem. Soc. 77, 5808-5814.

MiRSKAYA, K. V. (1973). Tetrahedron, 29, 679-682.

Mirskaya, K. V. (1976). Acta Cryst. A32, 199-207.

Rinaldi, R. P. \& Pawley, G. S. (1973). Nuovo Cimento B, 16, 55-62.

SKORCZYCK, R. (1976). Acta Cryst. A32, 447-452.

Vega, R., Hernández-Montis, V. \& López-Castro, A. (1976). Acta Cryst. B32, 1363-1366.

Williams, D. E. (1971). Acta Cryst. A27, 452-455.

Williams, D. E. (1972). Acta Cryst. A28, 629-635.

Williams, D. E. (1974). Acta Cryst. A30, 71-77.

Williams, D. E. \& Cox, S. R. (1984). Acta Cryst. B40, 404-417.

Acta Cryst. (1987). B43, 202-209

\title{
Structure and Charge Density of the 1:1 Complex of Thiourea with Parabanic Acid at $298 \mathrm{~K}$
}

\author{
By H.-P. Weber and B. M. Craven \\ Department of Crystallography, University of Pittsburgh, Pittsburgh, PA 15260, USA
}

(Received 18 June 1986; accepted 7 October 1986)

\begin{abstract}
The crystal structure of the 1:1 complex of thiourea $\left(\mathrm{CH}_{4} \mathrm{~N}_{2} \mathrm{~S}\right)$ and parabanic acid $\left(\mathrm{C}_{3} \mathrm{H}_{2} \mathrm{~N}_{2} \mathrm{O}_{3}\right)$ at $298 \mathrm{~K}$ has been redetermined from $\mathrm{X}$-ray intensity data (Mo $K \alpha, \sin \theta / \lambda<0.9 \AA^{-1}$ ). The space group is

$P 2_{1} / m$ (not $P 2_{1}$ as previously reported) with two molecules of each kind in the unit cell. Crystal data $\left[M_{r}=142 \cdot 18, F(000)=148\right]$ are: $a=10 \cdot 874(4), b=$ $6.152(5), c=6.161(3) \AA, \beta=114.39(3)^{\circ}$ at $93 \mathrm{~K}$; $a=10.893(5), \quad b=6 \cdot 229(6), \quad c=6 \cdot 160(3) \AA, \quad \beta=$ $114.31(4)^{\circ}$ at $213 \mathrm{~K} ; a=10.916(2), b=6.292(2)$,

(C) 1987 International Union of Crystallography 